\title{
Variation of Tensile Properties of High Silicon Ductile Iron
}

\author{
Peter Hammersberg ${ }^{1, a}$, Kenneth Hamberg ${ }^{1, b}$, Henrik Borgström ${ }^{2, c}$, \\ Joachim Lindkvist ${ }^{3, d}$ and Lars-Erik Björkegren ${ }^{4, e}$ \\ ${ }^{1}$ Chalmers University of Technology, Gothenburg, Sweden \\ ${ }^{2}$ Swerea SWECAST AB, Jönköping, Sweden \\ ${ }^{3}$ Volvo Powertrain, Gothenburg, Sweden \\ ${ }^{4}$ LEB Casting Technology, Jönköping, Sweden \\ apeter.hammersberg@chalmers.se, bk_hamberg@telia.com, chenrik.borgstrom@swerea.se*, \\ djoachim.lindkvist@volvo.com, ${ }^{9}$ leb@castingtechnology.se \\ ${ }^{*}$ corresponding author
}

\begin{abstract}
Keywords: Ductile iron, high silicon, solution hardening, gating system, tensile properties
\end{abstract}
\begin{abstract}
The casting processes are characterized by complex relationships between predictors and responses. It is the fundamental understanding of these complex relationships that often involves hundreds of factors, which improves quality without losing productivity and raising cost. In this work, cast solid solution strengthened ferritic spheroidal graphite irons GJS-500-14 and GJS-600-10 (EN 1563:2012) have been evaluated. These materials offer stronger components with good machinability owing to their even hardness properties. In this case the predictors are chemical composition, gating layout, foundry set-up, testing procedure and equipment etc. and the responses are the tensile properties $\left(\mathrm{R}_{\mathrm{p} 0.2}, \mathrm{R}_{\mathrm{m}}, \mathrm{A}_{5}\right)$. Here 200 tensile specimens compiled from industrial foundry melts from over 30 years of research have created a state-of-the-art platform for statistical engineering in order to perform Exploratory Data Analysis (EDA) and data visualization. This statistical platform has provided new insight on how foundries should treat complex relationships between predictors and responses in order to identify sources of variation and interaction effects.
\end{abstract}

\section{Introduction}

Research on cast solid solution strengthened ferritic spheroidal graphite iron with high silicon content (HSI), originally started in order to enhance machinability and reach the same or higher mechanical properties as ferritic/pearlitic GJS-500-7 [1]. The combination of high ductility and high yield strength has baffled the scientific community [2]. Traditionally, GJS-500-7 is one of the bulk materials for truck producers. This alloy had machinability issue, like short tool life and due to variations in the pearlite content (variations in hardness). Generally, the industry has been reluctant to use high silicon content in ductile iron, since chunky graphite often appeared in thick sections. In later years chunky graphite has been eliminated in production of HSI like GJS-500-14 [3]. For the stronger GJS-600-10, with even higher silicon content than GJS-500-14, action against chunky graphite has to be taken. Here antimony and cerium levels are adapted to eliminate chunky graphite $[4,5]$.

Benefits from HSI are a stronger component with very even properties which is a base for a more optimized and light component. More or less all hardness variations [1] have almost disappeared for GJS-500-14 alloys. A common disbelief is that ductility is low if the silicon content is raised, which is not necessarily true [2]. According to the standard (EN 1563:2012) HSI alloys GJS 500-14 and GJS 600-10 have around 100\% higher fracture strain and 9-18\% higher yield strength compared to normal GJS-500-7 with equal strength. However, excellent ductility if the silicon content is lower than $4.3 \mathrm{wt} \%$ has been found [6,7]. Here cost has been lowered as machinability increases with this material leading to advanced tolerances and longer tool life $[3,8]$. 
In this work identifying sources of variation, interaction-effects and predicting their influence on the tensile properties has been the main focus. The mechanical properties of more than 200 tensile specimens from industrial foundry melts have been compiled from over 30 years of research. This has provided an extensive material for Exploratory Data Analysis (EDA), data visualization and future multivariate data analysis and predictive modelling using utilizing state-of-the-art platforms for statistical engineering. Finally, new light has been shed on how foundries should treat complex relationships between process predictors and mechanical responses.

\section{Materials and Experiments}

More than 200 different tensile specimens ranging from 2.3 to $5.3 \mathrm{wt} \% \mathrm{Si}$ have been evaluated, originating from 9 test series at 3 different foundries over a time frame of 30 years (Fig. 1). Tensile test specimens were manufactured (according to SS-EN-ISO-6892-1:2016 A224 or internal AB Volvo standard) in a production like environment from plates, cylinders or components, with some wall thicknesses ranging from 10 to $200 \mathrm{~mm}$. The following parameters have been studied that related to tensile strength $\left(\mathrm{R}_{\mathrm{p} 0.2}, \mathrm{R}_{\mathrm{m}}, \mathrm{A}_{5}\right)$ :

- chemical composition with optical emission spectroscopy (OES)

- nodularity

- nodule count

- amount of chunky graphite

- amount of pearlite

- number of particles at the eutectic cell boundaries

According to the standard for HSI (EN 1563:2012), the required tensile properties for GJS-500-14 and GJS-600-10 are 400 and $450 \mathrm{MPa}$ in yield stress, 500 and $600 \mathrm{MPa}$ in tensile strength and 14 and $10 \%$ in ductility, respectively.

To elucidate the effect of the above parameters the chemical composition of the 200 tensile specimens represents the lowest and highest levels for several key elements utilized in the HSI base iron charge for normal foundry production. To do this OES has provided the final bulk chemical composition. However, an OES issue with HSI is that available high alloy calibration standards (SIMO CRM) are less suitable for the determination of Si. Hence, gravimetric analysis [4], where Si is dissolves in perchloric $\left(\mathrm{HClO}_{4}\right)$ acid has been used, as it provides far more accurate $\mathrm{Si}$ analysis than OES. Here a Gauge R\&R (repeatability and reproducibility) comparison between gravimetric analysis and OES showed that; Gravimetric analysis had a Gauage R\&R of $20 \%$ and OES had a Gauge R\&R of $50 \%$, respectively [9]. Another challenging element for OES is $\mathrm{Mg}$ that was underestimated by almost $20 \%$ by OES compared to Inverse Coupled Plasma (ICP) analysis. Surprisingly, $\mathrm{Ce}$ and $\mathrm{Sb}$ in the same work showed that OES had satisfactory Gauge R\&R despite of their low concentrations. Therefore, For the purpose of robustness OES has been compared to ICP analysis where the sample is dissolved in acid to facilitate lower detection limits for micro-alloyed elements like $\mathrm{Ce}, \mathrm{Sb}, \mathrm{Mg}$ etc. The $\mathrm{Mn}$ concentration was chosen over a wide span of 0.2 to $0.4 \mathrm{wt} \%$ to investigate preconceptions that only the lower contents can achieve high ductility. The copper level was kept below $0.2 \mathrm{wt} \%$ to suppress pearlite formation. $\mathrm{C}$ and Si levels of the HSI were adjusted in the melting furnace to the appropriate levels in terms of the carbon equivalent prior to the Mg-treatment. Sb in combination with $\mathrm{Ce}$ is important for the toughness. Reason for this is that they prevent formation of chunky graphite. In this work $\mathrm{Sb} / \mathrm{Ce}$-quota is equal to 1 . All experiments were carried out in furan sand molds.

\section{Results and Discussion}

The overall yield and tensile strength increases linearly with increasing silicon content up to a certain level as seen in Fig. 1. Ductility decreases linearly at the same time more or less to zero at $5.3 \mathrm{wt} \%$. For GJS-600-10, with Si-content roughly between 4.2 and $4.5 \mathrm{wt} \%$ the variation of 
ductility ranges from above $20 \%$ to almost zero as seen in the marked box of Fig. 1, compared to the lower specification limit (LSL) of ductility of $10 \%$. Understanding the reasons for this huge variation is the first step towards controlling the production process of high-strength and high ductility HSI. From Fig. 1, it is important to understand what to strive for in the samples with high ductility (+ markers), medium OK ductility $(\bullet)$ and what to avoid in brittle irons (o), since it seems possible to have both brittle and ductile irons with the same strength.

Stratification on grade shows that GJS-500-14, below $4.0 \mathrm{wt} \% \mathrm{Si}$, has a significantly less spread in fracture elongation than GJS-600-10, which emphasizes increased sensitivity to variation for the high Si contents. The reason for the variation in GJS-600-10 must be mapped and understood if robust tensile properties are to be achieved. GJS-500-14, on the contrary, is in production at several locations successfully [3].

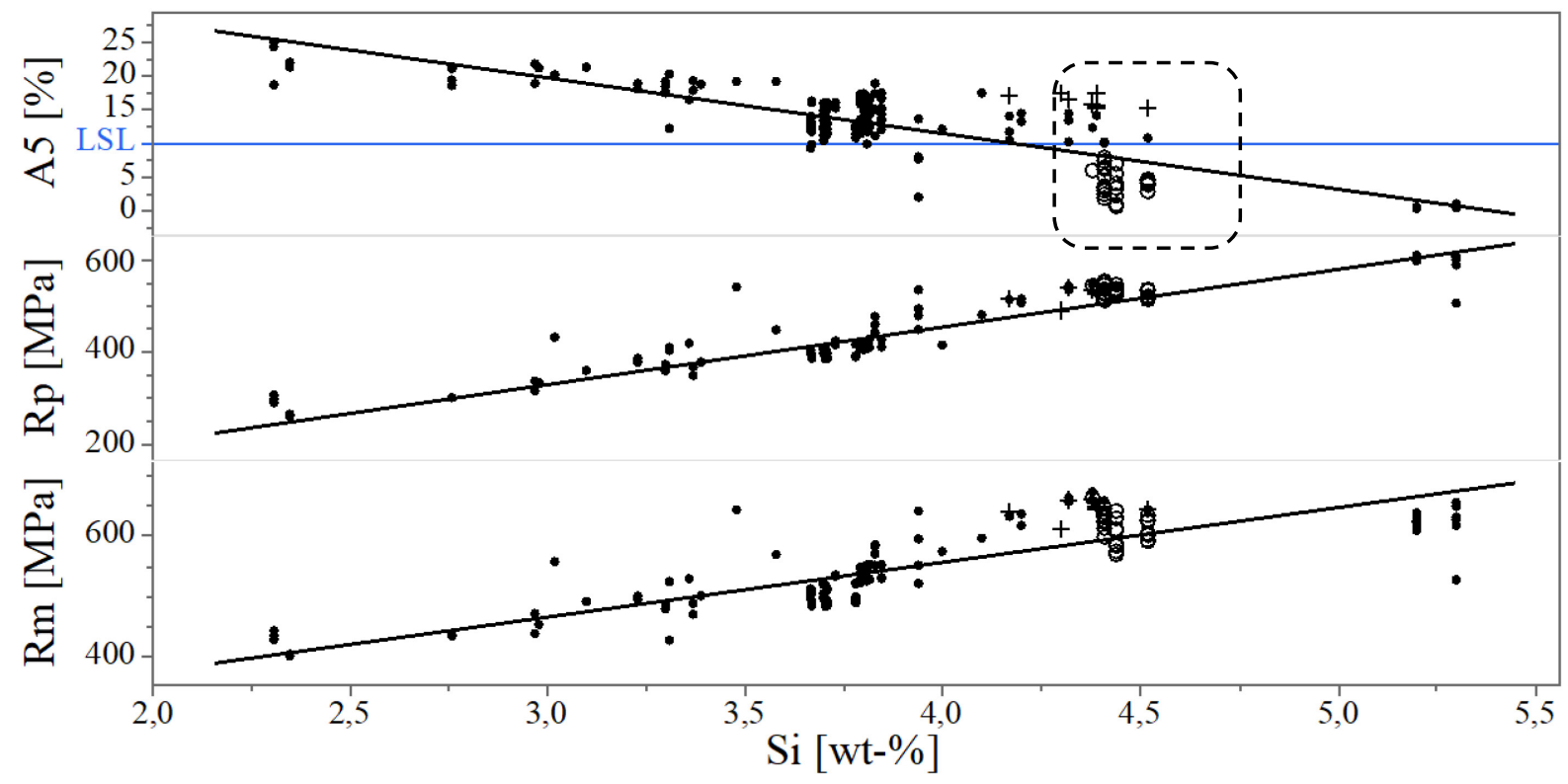

Fig. 1: Influence of silicon level on the tensile properties, with boxed GJS- 600-10 samples for the ductility and optimal runners indicated with + .

\section{Influence of Section Thickness}

The section thickness independence seen in Fig. 2 is likely a result of the solution hardening of ferrite. The thicker sections are affected only by the size and number of graphite nodules. However, both thin and thick sections are brittle or ductile. It can also be seen that scatter in ductility of GJS600-10 is larger than GJS-500-14 ( $<4 \mathrm{wt}-\% \mathrm{Si}$ ). For GJS-500-14 the influence of section thickness seems to be negligible above $50 \mathrm{~mm}$ wall thickness. For thinner sections the scatter is greater, but the influence is low. For yield and tensile strength, only a minor difference exists between GJS-50014 and GJS-600-10 in wall thickness dependence, apart from that the strength is higher in GJS-60010 material. 


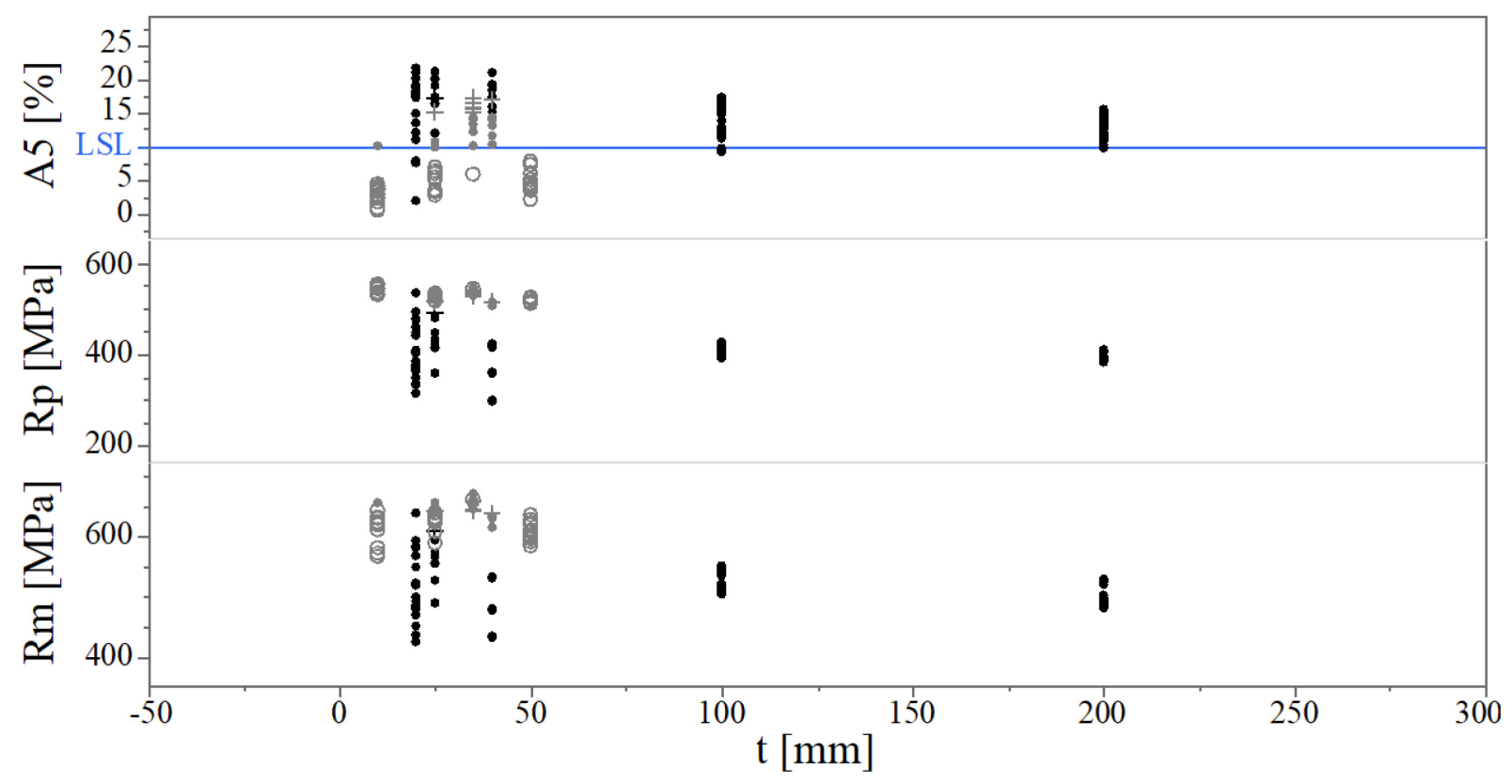

Fig. 2: Influence of section thickness ( $\mathrm{t}$ ) on tensile properties, with GJS-500 in black and GJS-600-10 in grey.

\section{Influence of Tramp Elements}

To simplify the statistical treatment, all chemical elements that are not actively controlled are defined as tramp elements. These elements come with the charge (steel, alloys, pig iron etc.) or from other steps in the foundry process (linings etc.). In this work tramp elements are defined as:

$$
\text { Tramp elements }=\mathrm{Ni}+\mathrm{Cr}+\mathrm{Al}+\mathrm{Ti}+\mathrm{V}+\mathrm{Mo}+\mathrm{Zn}+\mathrm{Pb}+\mathrm{B}+\mathrm{N}[\mathrm{wt} \%]
$$

In Fig. 3, GJS- 600-10 shows little impact in ductility of tramp elements under $0.3 \mathrm{wt} \%$. GJS- 500-14 shows decreased strength with increasing number and amount of tramp elements.

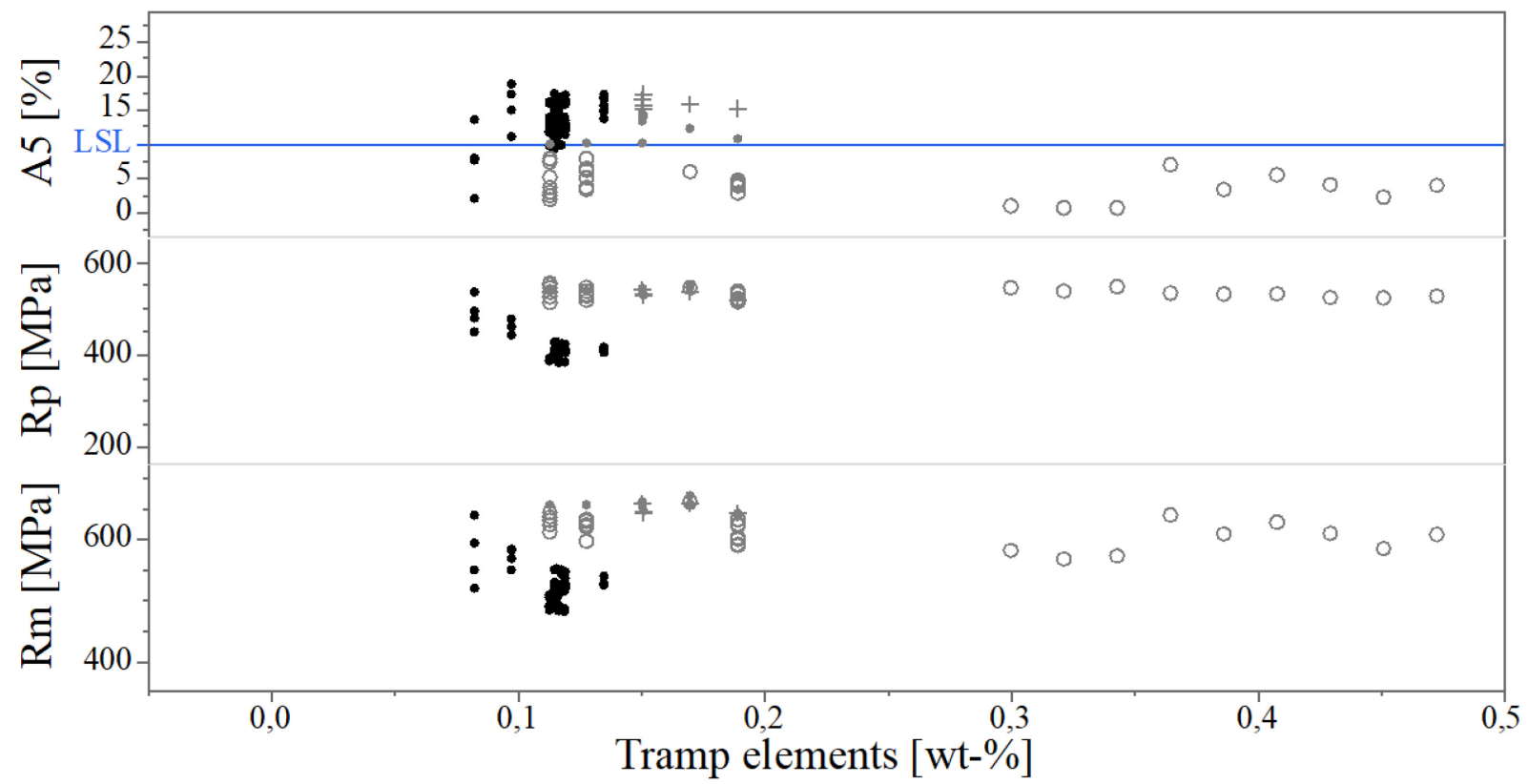

Fig. 3: Influence of tramp elements on the tensile properties. 


\section{Influence of Gating System}

For GJS-600-10, Fig. 4 stratifies ductility $\left(\mathrm{A}_{5}\right)$ whether an optimized gating system has been used or not. To the left, where ductility is low standard gating system is used. To the right, optimized gating systems produces high ductility. Both plates and components were cast with low inlets and with rising melt in an unpressurized system. Owing to propriety reasons, it is not possible to disclose details of the gating system, but everything was optimized according the specific foundry procedure. For non-optimized gating systems points close to the LSL line, it is obvious that something more than the gating system and chemical composition must be responsible for the good ductility in these cases. The outlier sample (lower than the LSL-line) for the optimized gating system was a shrinkage cavity on the fracture surface. The gating system does not affect yield strength in a significant way and is therefore not visualized.

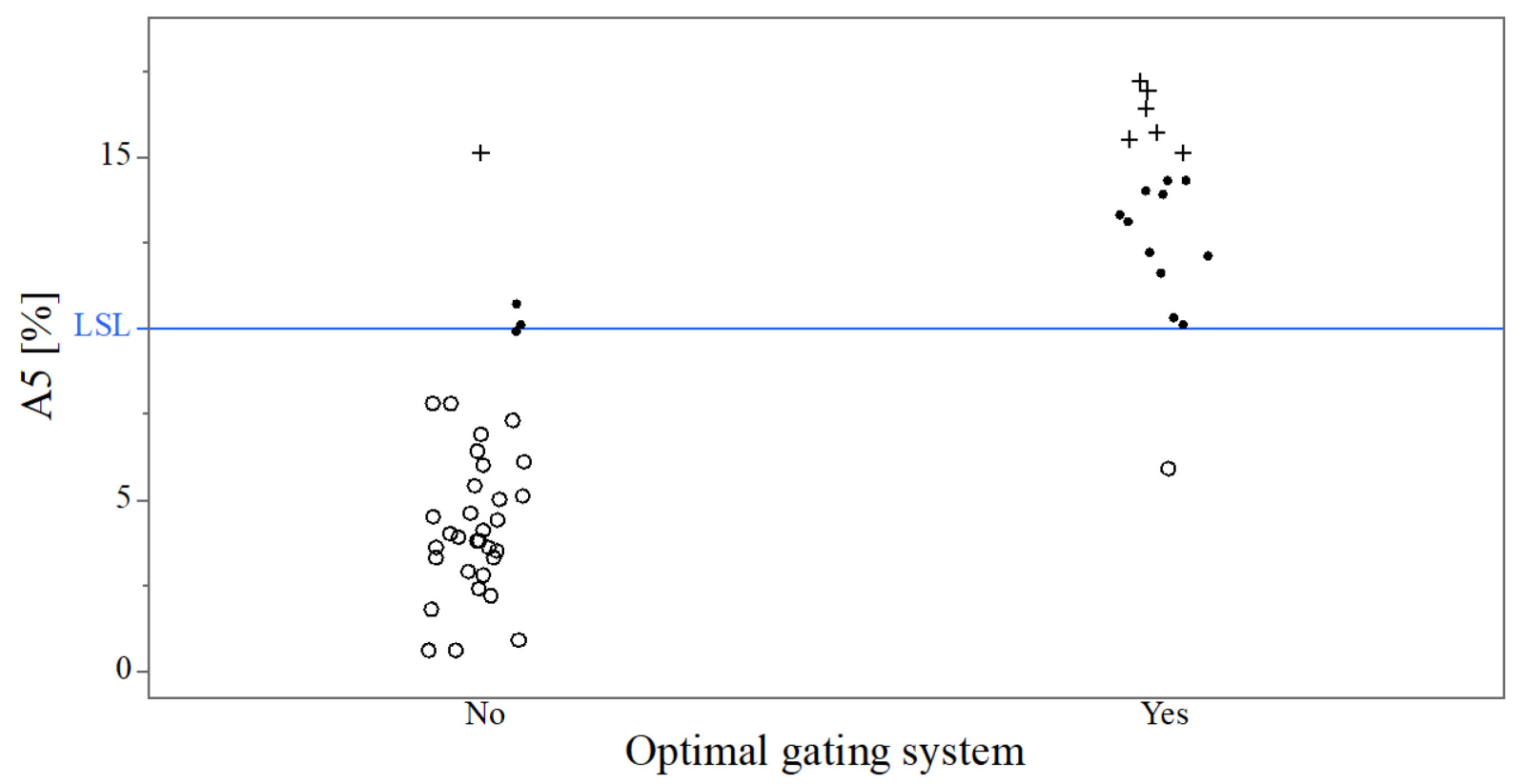

Fig. 4: Influence of optimal gating system (dark grey) on ductility $\left(\mathrm{A}_{5}\right)$ for GJS-600-10.

\section{Influence of Chemical Composition}

When ductility (elongation) is plotted against common figures of merit for the chemical composition in Fig. 5 some indications and tendencies are worthy of further discussion. In Fig. 5 a scatterplot matrix for residual magnesium content, phosphorus content, $\mathrm{Mg} / \mathrm{P}$-quota, $\mathrm{Sb} / \mathrm{Ce}$ ratio, Carbon equivalent $\left(\mathrm{C}_{\mathrm{eq}}=\mathrm{C}+\mathrm{Si} / 4+\mathrm{P} / 2\right)$, and Manganese against tensile properties like ductility is stratified on optimal and non-optimal gating systems, which are represented by data density ellipses that cover $90 \%$ of the data. Here a first conclusion is that an optimal gating system is not disadvantageous; a good gating system gives a higher ductility in most cases. 


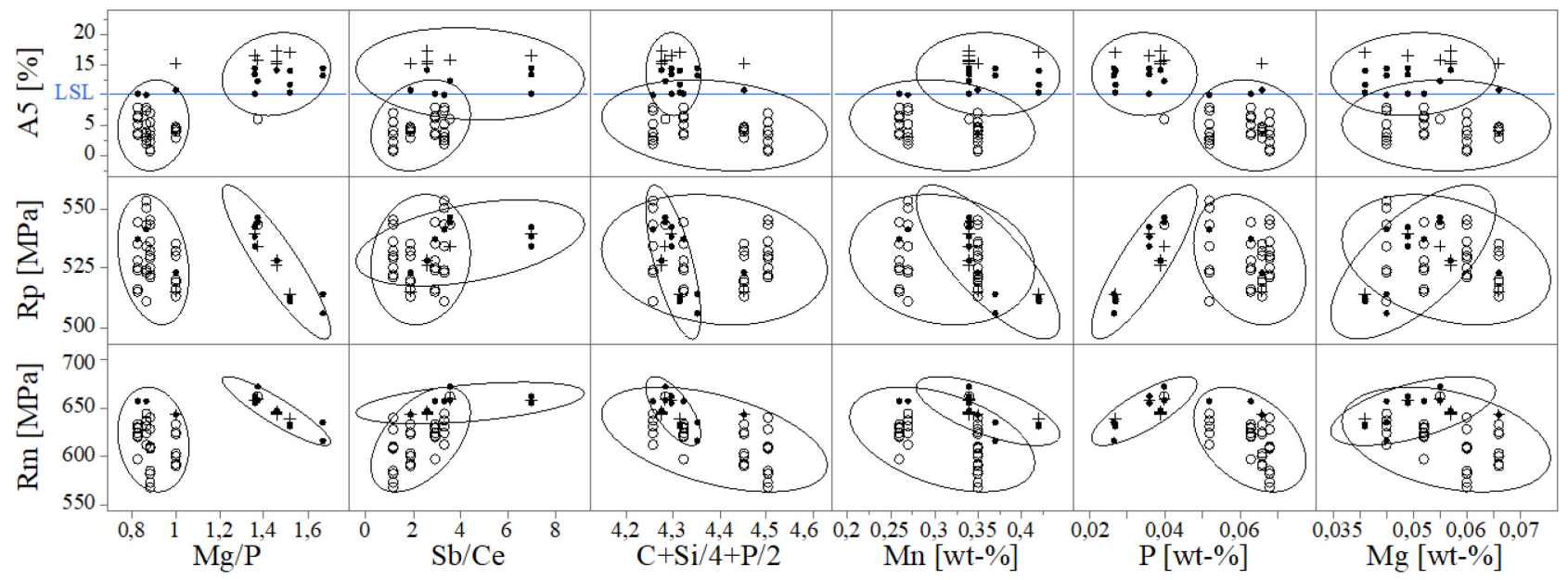

Fig. 5: Tensile properties for GJS-600-10 against several figures of merit for the chemical composition for optimal (ellipses containing most + markers) and non-optimal gating systems.

For an optimized gating system, the manganese content seems to play a subordinate role. Manganese is an important element in the charge at all foundries, since it comes with the steel scrap and influences cost. The higher manganese level, the cheaper the scrap will be. Therefore, it is important to state the manganese level can be rather high in GJS-600-10 without an influence on ductility. In this work, levels up to $0.4 \mathrm{wt} \%$ can be tolerated. This statement is valid provided the casting system is optimized. Strength is more or less unaffected. Manganese is a medium solution hardener of ferrite.

Carbon and silicon should have a relatively low impact on toughness in the small interval which is available in GJS-600-10. However, the prevalence of naturally brittle hyper eutectic carbon equivalents cannot be ignored, even if it is clear that optimal runners have a positive impact on ductility for the near eutectic populations.

$\mathrm{Sb} / \mathrm{Ce}$ ratio seems to weakly benefit in terms of tensile strength from an optimum gating system, which is expected.

Low phosphorus conditions $(<0.04 \mathrm{wt} \% \mathrm{P})$ with high $\mathrm{Mg} / \mathrm{P}$-quota $(>1.3)$ are favorable in a ductility perspective. From Fig. 5 it is also clear that a non-optimum gating system with high phosphorus content can provide good ductility, which is unexpected. Another unanswered question is what is most important: low phosphorus content or high $\mathrm{Mg} / \mathrm{P}$-quota? Reason for this is that there seems to exist a coupling between the two parameters. In this work, high $\mathrm{Mg} / \mathrm{P}$-quota with a high $\mathrm{P}$ content and a low $\mathrm{Mg} / \mathrm{P}$-quota with low P-content combinations was missing, but should be included in a future full parameter experimental study. Here, there is a danger that the beneficial potential for solid solution hardening of P in HSI is impeded by its strong segregation tendency, which usually leads to hard Steadite areas in the eutectic cell boarders. Or that it cannot be used in foundry practice as an alloying element. Residual magnesium content does not seem to affect ductility or the strength parameters in a significant way, as long as the level lies within standard specification. Experiments in this work indicate that the residual magnesium levels are not so critical. For optimal gating in Fig. 5, ductility seems relatively insensitive to excessive Mg contents.

It is difficult to draw firm conclusions on the effect or influence of individual elements on ductility since there are natural correlations in full size foundry test series. For example, in Fig. 5, phosphorus versus ductility, it is shown that highest ductility samples have a phosphorous level between 0.03 and $0.04 \mathrm{wt} \%$ for an optimized gating system. Also, ductile samples $(+)$ have higher copper levels, but the correlation plot between phosphorous and copper shown that these elements are correlated. Beside the gating system the phosphorus level must be less than $0.04 \mathrm{wt} \%$ in order to get higher ductility. 


\section{Influence of Defects and Cell-boundary Segregation}

Fig. 6 shows an example of what segregation can cause. The amount of phosphorus and residual magnesium were high even in this case. Phosphorus has a solid solution capability, but in excess it can form cell boundary Steadite as seen in Fig. 6. Pearlite stabilizing elements segregate to the last melt to solidify and make the cell boundary hard and less ductile. Fig. 6 shows that an excess of residual magnesium can give magnesium oxides in the eutectic cell boundary which probably lowers ductility. Again, ductility increases for an optimized gating system, which is also likely for other ductile irons. The other two strength parameters seem to be unaffected. In Fig. 6 one can see that hard particles in the cell boundary, which can cause crack initiation Spectrometer analysis of these particles showed peaks of Fe, Si and N. The small particles at the cell boundaries had a Mo peak. This element comes with the charged steel scrap. Consequently, hard particles at the cell boundaries must be avoided in a solution strengthened ferritic matrix

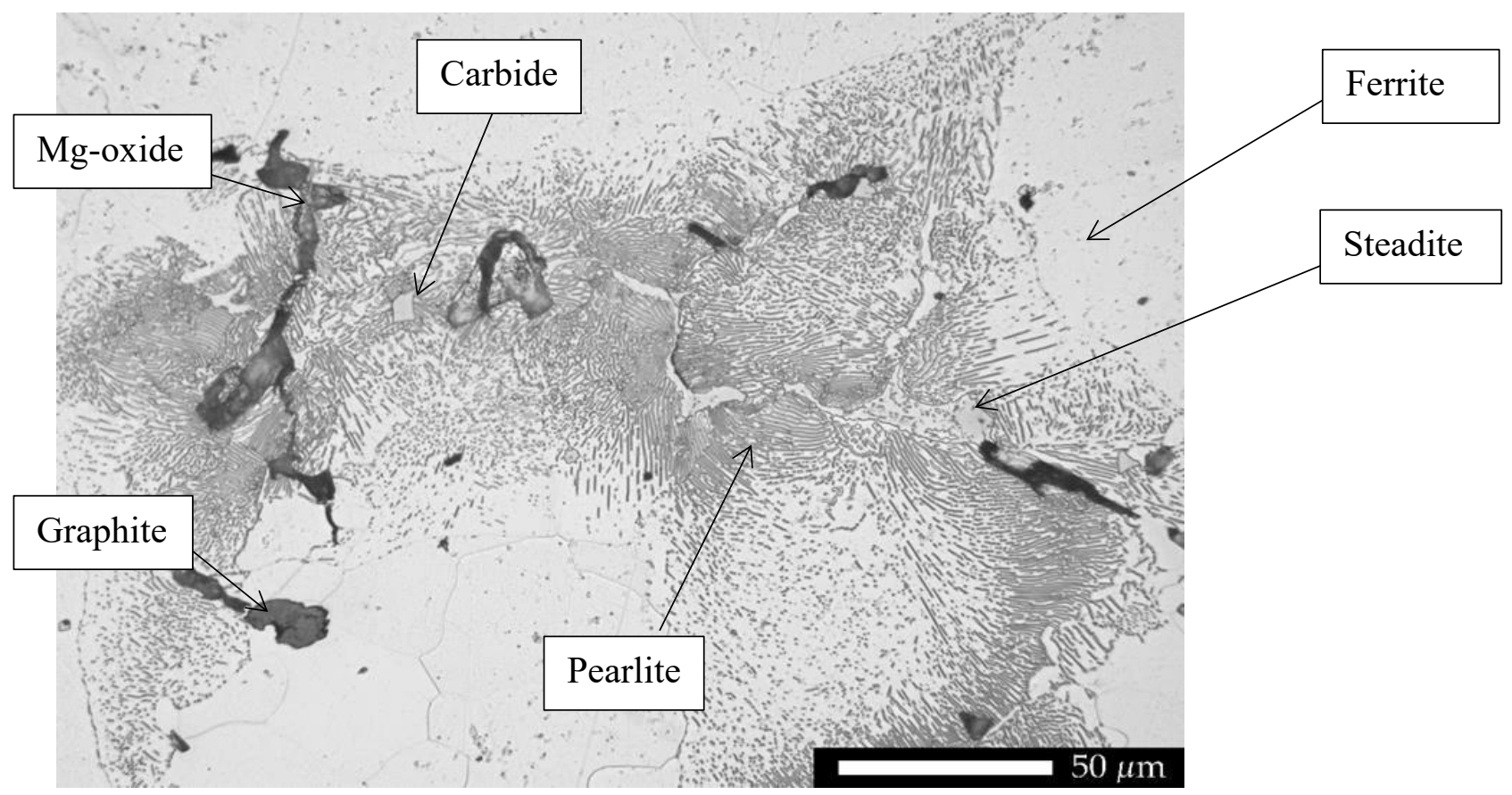

Fig. 6: Example of a contaminated cell boundary.

\section{Conclusions}

From 200 tensile specimens from over 30 years research it has been shown that strength increases linearly and ductility decrease linearly in the Silicon content range 2.3 to $5.3 \mathrm{wt} \%$. In addition, section thickness independence has been observed for the same interval. Up to a Silicon content of $4 \mathrm{wt} \%$ the variation in tensile properties is limited and predicable, which explains why GJS- 500-14 is produced industrially. However, if HSI with more than 4 wt $\%$ Silicon like GJS-60010 is to be produced industrially the reason for the increased variation in its properties must be mapped and understood. Here the performance of the gating system is essential to fulfil GJS-600-10 specification. For optimized gating system, the influence of chemical composition can be controlled to a greater extent than in non-optimized conditions, where unknown mechanisms prevail. In particular, conditions with low phosphorus content, less than $0.04 \mathrm{wt} \%$ and a high $\mathrm{Mg} / \mathrm{P}$-quota $(>1.3)$ are favorable in a ductility perspective with limited influence on strength. Furthermore, for an optimized gating systems Mn content up to $0.4 \mathrm{wt} \%$ can be tolerated without loss of strength and ductility, which influences charge cost favorably. If the foundry can use optimized gating systems to higher extent it would be possible to tailor the charge to meet the customers demand. Consequently, it must be understood that good properties in the components is achieved only if the foundry process is run according to best practice. 


\section{References}

[1] L-E Björkegren, Ferritic Ductile Iron with High Silicon Content, Swerea SWECAST Report 941028, In Swedish, (1994)

[2] Ductile Iron, Molten Metal Processing", 2ed, American Foundrymen's Society, Inc, (1986)

[3] R. Larker, Solution Strengthened Ferritic Ductile Iron ISO 1083/JS/500-10 provides superior consistent properties in hydraulic Rotors, Keith Millis Symposium on Ductile Iron, (2008)

[4] H. Borgström. Methods for limiting Chunky Graphite in Ductile Iron, Swerea SWECAST report G932J, Jönköping, (2015)

[5] A. Alhussein, M. Risbet, A. Bastien, J. P. Chobaut, D. Balloy, J. Favergeon, Influence of Silicon and addition elements on the mechanical behavior of ferritic ductile cast iron, Mat Sci Eng A - Struct, 605 (2014), 222-228.

[6] H. Löblich et. al, Gusseisen mit Kugelgraphit profitiert vom hohen Siliziumgehalte, Maschinen Markt, 41 (2011), 42-46.

[7] H. Löblich, W. Stets, G. Gassner, Hoch Silicium Gehalte Gusseisen mit Kugelgraphit toleriert Größere Anteile an Carbid bildenden Elementen, Gießerei, Nr. 4. (2012), 24-28.

[8] G. Gassner, W. Bauer, P. Schumacher, Werkstoff-und fertigungstechnische Grundlagen der Herstellung und Anwendung von hoch Silicium haltigem Gusseisen mit Kugelgraphit, Gießerei, Nr. 5 (2012), 18-20. 